\title{
British Association of Dental Therapists
}

$\mathrm{T}$ he British Association of Dental Therapists (BADT) was formed in 1962 by the first graduates of the School for Dental Auxiliaries in New Cross, London, which had opened two years earlier as the only training school in the Northern Hemisphere. The first AGM was held on 2 March 1963. BADT is the longest running dental therapy association in the UK and Europe, and second in the world behind New Zealand.

Dental therapists (or auxiliaries as they were known originally) were introduced to address the dental manpower shortage of the time and the rising childhood caries incidence. Fifty 'young women, all aged 17-25 and single' were recruited and followed a rigorous two-year training. Upon qualification they were confined to treating children (18 and under) in community dental clinics within the framework of the NHS.

Since that time, BADT has supported and driven the profession forward securing professional indemnity in 1964, and then acceptance as members by the Medical Protection Society. BADT has been central to all the major decisions affecting dental therapists and their progression in the profession including:

- The introduction of 'extended duties' training in 1997 in: pulpotomies, preformed metal crowns, impression taking and ID blocks

- Working in general dental practice in 2002

- Removing the restriction to have a dentist on the premises when treating patients

- Direct Access for both dental therapists and dental hygienists in 2013, in spite of initial reluctance by some parties to allow it for dental therapy

- Working to secure the correct grading for members during the introduction of Agenda for Change pay scales.

\section{Current projects include:}

- Working with the British Society of Dental Hygiene and Therapy (BSDHT) to secure 'Exemptions' to prescribing rights to allow prescription of local anaesthetic and certain medicaments such as topical fluoride

- Lobbying the GDC to revise its registration criteria for overseas trained personnel to be admitted to the register with an assessment of practical ability. There has been a huge rise in the number of overseas trained dentists who are opting to register via this route as it avoids the overseas registration exam (ORE). This assessment is a paperwork exercise, matching learning outcomes only at present

- Key roles in General Dental Council (GDC) reform of complaints handling and 'Moving Upstream' consultations

- Engaging vigorously with the GDC to implement instalment payments for the annual retention fee (ARF) for all dental care professionals (DCPs)

- Supporting BADT members who have had NHS payments withheld during the COVID pandemic. Producing both our own position statement and working in collaboration with the British Dental Association (BDA)

- Driving for contract reform to allow greater patient access to NHS care by better use of dental therapists

- Meeting with MPs and ministers to raise awareness of the skills and benefits of utilising dental therapists in the team more effectively.

Last year BADT were invited to join the International Oral Health Association, a worldwide dental therapists' collaboration, and Debbie McGovern, BADT President, was invited to sit on their executive committee.

Debbie McGovern is also the DCP representative on the board of the newly formed British Association of Private Dentistry.

Chair, Debbie Hemington, sits on the Dental Professionals Alliance committee, represents BADT at the British Society of Periodontology and is in one of the working parties for the upcoming revision to Delivering better oral health.

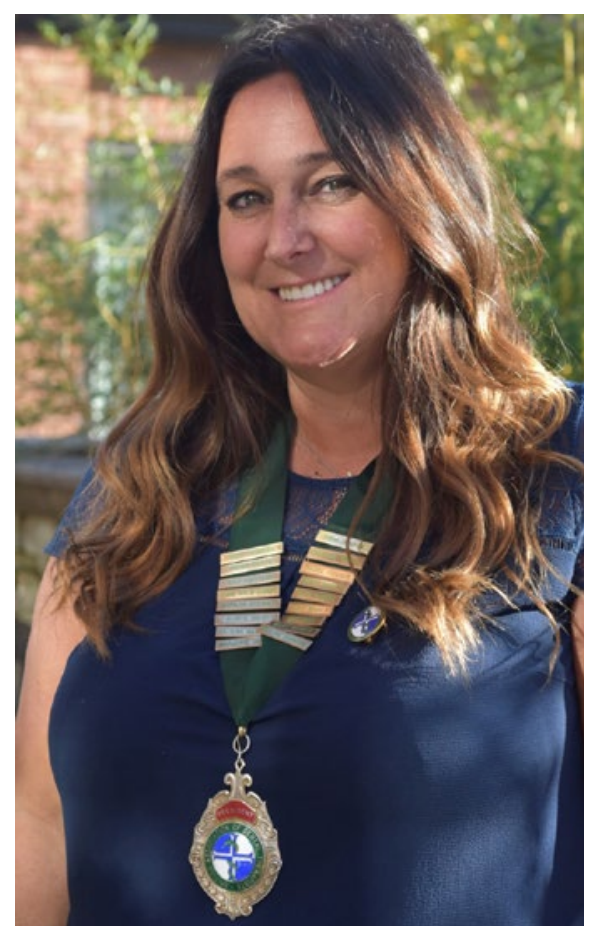

Current President of BADT, Debbie McGovern

Membership of BADT has increased dramatically during the pandemic, mainly due to the help offered with disputes over NHS pay, and subscription costs were suspended to allow access to members who were facing financial hardship during this time.

Membership is open to all registered dental therapists and hygienists (the scope of practice of a dental therapist includes all elements of the dental hygienist scope as well as the restorative elements for dental therapy). New members can join online at www.badt.org.uk, and benefits of membership include:

- A members' hotline for advice

- Legal support via BADT's legal partner

- HR and employment support

- Representation of dental therapists and hygienists at local, national, and international level

- Regular members only webinars

- Dedicated Dental Therapy Update journal

- Free access to Dental Update online

- Access to RDH e-magazine

- Discounted members' rates at the annual conference and regional study days

- Discounts on many CPD courses

- Local support from a regional representative

- 'Zoom' coffee morning for keeping in touch.

BADT has remained an association run by working dental therapists, for the benefit of the profession. 